\title{
Calmodulinopathy: Functional Effects of CALM Mutations and Their Relationship With Clinical Phenotypes
}

\author{
Beatrice Badone ${ }^{1}$, Carlotta Ronchi ${ }^{1}$, Maria-Christina Kotta ${ }^{2}$, Luca Sala ${ }^{2}$, Alice Ghidoni ${ }^{2}$, \\ Lia Crotti ${ }^{2,3+}$ and Antonio Zaza ${ }^{1 * t}$ \\ ${ }^{1}$ Department of Biotechnology and Bioscience, University of Milano-Bicocca, Milan, Italy, ${ }^{2}$ Center for Cardiac Arrhythmias of \\ Genetic Origin and Laboratory of Cardiovascular Genetics, Istituto Auxologico Italiano, IRCCS, Milan, Italy, ${ }^{3}$ Department of \\ Medicine and Surgery, University of Milano-Bicocca, Milan, Italy, ${ }^{4}$ Department of Cardiovascular, Neural and Metabolic \\ Sciences, San Luca Hospital, Istituto Auxologico Italiano, IRCCS, Milan, Italy
}

\section{OPEN ACCESS}

Edited by: Gaetano M. De Ferrari, University of Pavia, Italy

Reviewed by:

Osmar Antonio Centurion, Universidad Nacional De Asunción,

Paraguay

Anna Pfenniger, Northwestern Medicine United States

*Correspondence: Antonio Zaza antonio.zaza@unimib.it

tThese authors share senior authorship

Specialty section: This article was submitted to Cardiac Rhythmology,

a section of the journal

Frontiers in Cardiovascular Medicine

Received: 05 September 2018 Accepted: 22 November 2018 Published: 11 December 2018

Citation:

Badone B, Ronchi C, Kotta M-C, Sala L, Ghidoni A, Crotti L and Zaza A (2018) Calmodulinopathy: Functional Effects of CALM Mutations and Their Relationship With Clinical Phenotypes. Front. Cardiovasc. Med. 5:176. doi: 10.3389/fcvm.2018.00176
In spite of the widespread role of calmodulin (CaM) in cellular signaling, CaM mutations lead specifically to cardiac manifestations, characterized by remarkable electrical instability and a high incidence of sudden death at young age. Penetrance of the mutations is surprisingly high, thus postulating a high degree of functional dominance. According to the clinical patterns, arrhythmogenesis in CaM mutations can be attributed, in the majority of cases, to either prolonged repolarization (as in long-QT syndrome, LQTS phenotype), or to instability of the intracellular $\mathrm{Ca}^{2+}$ store (as in catecholamine-induced tachycardias, CPVT phenotype). This review discusses how mutations affect CaM signaling function and how this may relate to the distinct arrhythmia phenotypes/mechanisms observed in patients; this involves mechanistic interpretation of negative dominance and mutation-specific CaM-target interactions. Knowledge of the mechanisms involved may allow critical approach to clinical manifestations and aid in the development of therapeutic strategies for "calmodulinopathies," a recently identified nosological entity.

Keywords: calmodulin mutations, ion channels, repolarization, $\mathrm{Ca}^{2+}$ handling, arrhythmia mechanisms

\section{INTRODUCTION}

As other ions, $\mathrm{Ca}^{2+}$ is used as a charge carrier to modulate membrane potential; however, $\mathrm{Ca}^{2+}$ also has a central role as a diffusible signaling molecule and as a trigger of diverse cellular functions. While some of these are clearly complementary in achieving a functional goal (e.g., cAMP signaling in functional upregulation) and can coexist, others are devoted to apparently competing aims (e.g., apoptosis pathway) and need to be separated. This requires mechanisms allowing intracellular $\mathrm{Ca}^{2+}$ to act on its targets with high specificity. Several strategies are employed by the cell to achieve this goal. $\mathrm{Ca}^{2+}$ buffering by intracellular proteins and small molecules, leads to a strictly controlled mobility of the ion. Active $\mathrm{Ca}^{2+}$ compartmentalization within organelles allows to keep "resting" $\mathrm{Ca}^{2+}$ concentration in the general (or "bulk") cytosolic compartment at very low levels (around $10^{-7} \mathrm{M}$ ), i.e., below the threshold required to activate downstream effectors; at the same time, structural organization (e.g., T-tubules) allows very small $\mathrm{Ca}^{2+}$ fluxes to achieve high $\mathrm{Ca}^{2+}$ concentration in the specific subcellular compartment hosting the target effector (1). 
The presence of molecules devoted to detect $\mathrm{Ca}^{2+}$ and transduce its concentration changes into specific actions is a further strategy, pivotal to the integrated operation of $\mathrm{Ca}^{2+}$. dependent processes. Perhaps the most diffuse of such " $\mathrm{Ca}^{2+}$ sensor" molecules is calmodulin (CaM), a protein present in all cell types and highly conserved throughout evolution (1). Most $\mathrm{Ca}^{2+}$-binding proteins are characterized by "EF hand" domains, which constitute the ion binding site. Whereas, in proteins involved in $\mathrm{Ca}^{2+}$ buffering and controlled mobility the EF hand is simply a binding site, in $\mathrm{Ca}^{2+}$ sensors the EF domain changes protein conformation in response to $\mathrm{Ca}^{2+}$ binding, thus triggering a variety of downstream events (2).

Essential to CaM's targeting role, is its property to stably bind to many of its downstream effectors. This corresponds to the presence on the latter of specific CaM-binding sequences, which make CaM an integral component of the target protein. Thus, CaM can exist as a freely diffusible signal (cytosolic pool), or as a sensor intrinsic to a given effector (bound pool), thus affording either diffuse or highly confined signaling. Furthermore, in various cells types, the cytosolic CaM pool can be redistributed to the nuclear compartment upon a rise in $\mathrm{Ca}^{2+}$ levels, thus broadening the targets range $(3,4)$. Also, except in selected cell types (e.g., mitotic cells), local CaM concentrations may follow $\mathrm{Ca}^{2+}$ oscillations, thus generating spatial and temporal patterns which may play a crucial role in biological processes (5).

In keeping with its central and evolutionarily conserved function, CaM is generated in a highly redundant mode. Indeed, an identical amino acid sequence is encoded by $3 \mathrm{CaM}$ genes (CALM 1, 2, and 3) (5). Such redundancy is in apparent contrast with the high penetrance of heterozygous CaM mutations. While the possible role of transcriptional regulation of these genes is discussed in the accompanying article (6), specific molecular mechanisms may contribute to negative dominance in a mutation's effect.

In cardiac muscle cells, $\mathrm{Ca}^{2+}$ at the same time contributes as a charge carrier to electrical excitation (the "action potential," $\mathrm{AP}$ ) and triggers the development of mechanical force; therefore, $\mathrm{Ca}^{2+}$ is crucial to excitation-contraction coupling (ECC) (7). Several processes central to beat-to beat control of intracellular $\mathrm{Ca}^{2+}$ dynamics are CaM-mediated; furthermore, CaM acts a
$\mathrm{Ca}^{2+}$ sensor in the control of gene expression, thus playing a role in long-term modulation of cell function and fate (8). This might lead to the expectation that a CaM loss of function should result in general myocyte dysfunction and death. However, this is contradicted by the observation that $\mathrm{CaM}$ mutations affect only the function of specific targets, leading to mutation-specific phenotypes with pronounced electrical instability as a common feature (9).

Our objective is to revise the information available on the various aspects of CaM structure/function that we see as potentially relevant to a mechanistic interpretation of $\mathrm{CaM}$ mutations phenotypes, with a focus on cardiac ones.

\section{CaM Structure, $\mathrm{Ca}^{2+}$-Sensing and Target Recognition}

CaM is composed of 149 amino acid residues to form a $17 \mathrm{kDa}$ protein. The protein is ubiquitous and expressed in all eukaryotic cells, with $100 \%$ identity in its amino acid sequence among vertebrates. Three genes (CALM1, CALM2, and CALM3) encode $\mathrm{CaM}$ with an identical amino acid sequence, thus resulting in potential redundancy (10).

CaM is formed of two "lobes," named $\mathrm{N}$ and $\mathrm{C}$, respectively, according to their position with respect to protein ends, connected by an $\alpha$-helix "linker" containing a flexible region ("hinge") (Figure 1) (12); this allows each lobe to move relative to the other. Each lobe consists of two "EF hand" domains (EF) with one $\mathrm{Ca}^{2+}$ binding site each ( $2 \mathrm{Ca}^{2+}$ binding sites per lobe). All $\mathrm{EF}$ hand domains can bind $\mathrm{Ca}^{2+}$; however, while the N-lobe (EF I and EF II) has higher affinity for $\mathrm{Mg}^{2+}$, the C-lobe (EF III and EF IV) binds $\mathrm{Ca}^{2+}$ with ten times higher affinity (13). Another functional distinction between the two CaM lobes is the rate of $\mathrm{Ca}^{2+}$ binding and unbinding, faster for the N-lobe than for the C-lobe (14).

Knowledge of CaM's 3D structure has evolved since its first description in 1985 (15), with a major contribution provided, 10 years later, by nuclear magnetic resonance (16). Whereas, this technology revealed detail of the linker helix accounting for its flexibility $(17,18)$, more recent studies added information about recognition of target proteins and how it can be affected by CaM complexing with $\mathrm{Ca}^{2+}(12,19)$.

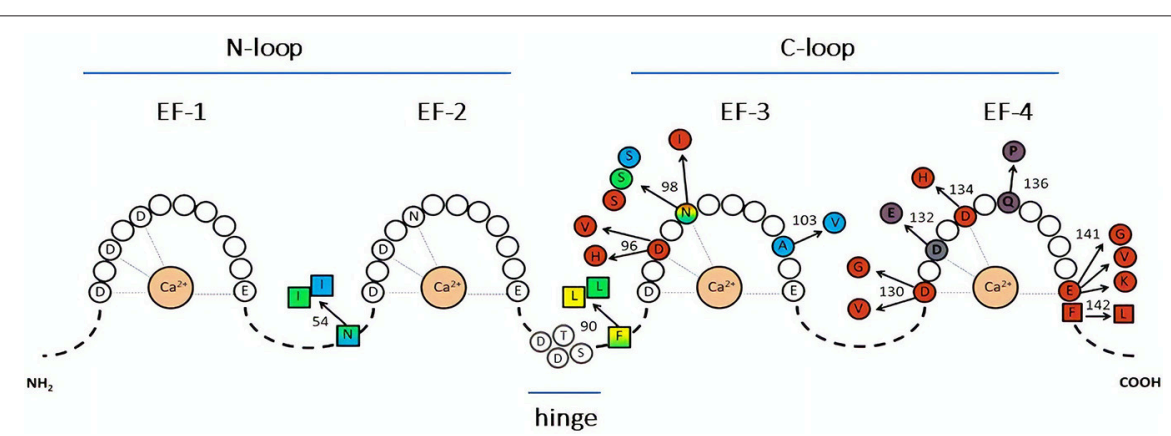

FIGURE 1 | Representation of CaM sequence and relative disease-associated mutations. The letters identify amino acids directly involved in Ca ${ }^{2+}$ binding (within the EF-hands), or in the hinge region. Color-substituted amino acids represent mutations in the EF-hands (circles) or in the linkers (squares); colors correspond to the associated phenotype: catecholaminergic polymorphic ventricular tachycardia (CPVT, light blue), long QT syndrome (LQTS, red), idiopathic ventricular fibrillation (IVF, yellow), other unexplained sudden death (green). LQTS/CPVT overlap mutations are shown in shaded color. Modified from Crotti and Kotta, (11). 
The interplay between structure and function is relevant to the three components of CaM signaling: $\mathrm{Ca}^{2+}$ binding, target binding, and target modulation.

The first aspect of interest is CaM's interaction with $\mathrm{Ca}^{2+}$. In apo-CaM (the $\mathrm{Ca}^{2+}$ unloaded CaM), EF I and EF II (N-lobe) are in a packed conformation, thus with low affinity for $\mathrm{Ca}^{2+}$; EF III and EF IV (C-lobe) are instead in a partially open conformation, more prone to $\mathrm{Ca}^{2+}$ binding. At resting $\mathrm{Ca}^{2+}$ levels (about $10^{-7}$ $\mathrm{M})$, all CaM binding sites are typically unoccupied. When $\mathrm{Ca}^{2+}$ rises, its binding to the $\mathrm{C}$-lobe sites triggers a conformational change leading the $\mathrm{N}$-lobe to increase its affinity for $\mathrm{Ca}^{2+}$. In other words, $\mathrm{Ca}^{2+}$ binding to $\mathrm{CaM}$ is "cooperative," i.e., the overall affinity increases when $\mathrm{Ca}^{2+}$ concentration exceeds the threshold for C-lobe occupation. CaM can potentially bind 1-4 $\mathrm{Ca}^{2+}$ ions; activation of downstream targets requires CaM being loaded with $3 \mathrm{Ca}^{2+}$ ions at least (12), a configuration referred to as "holo-CaM."

Also of interest are the structural aspects of CaM's interaction with target proteins, which are necessary for modulation of their activity. "Anchor" domains on target proteins are characterized by hydrophobic residue sequences flanked by negatively charged ones; the latter provide electrostatic interaction that may orient CaM binding (12). Many CaM targets (e.g., $\mathrm{Ca}_{\mathrm{V}} 1.2$ ) are characterized by the presence of a typical basic amino acid sequence called the "IQ motif." The IQ motif is closely preceded by a "preIQ" region, which is a common site of permanent CaM binding (20). CaM interaction with the IQ motif itself is instead more likely responsible for downstream signaling $(8,14)$; indeed, specificity of the IQ sequence may dictate whether $\mathrm{Ca}^{2+} \mathrm{CaM}$ signaling leads to target activation or inhibition (20). A wellstudied instance of preIQ-IQ binding is CaM interaction with the voltage-dependent L-type $\mathrm{Ca}^{2+}$-channel $\left(\mathrm{Ca}_{\mathrm{v}} 1.2\right)$; the detailed mechanism and $\mathrm{Ca}^{2+}$-dependency of this specific interaction will be described in paragraph Voltage-gated $\mathrm{Ca}^{2+}$ channels (Cav1.2).

As for $\mathrm{Ca}^{2+}$ sensing, CaM domains mainly involved in target binding are the lobes. Both CaM lobes contain nine methionine residues, playing a key role in target recognition, whose high flexibility provides plasticity crucial for this function (21).

The CaM binding interface is highly structured, but it may dynamically accommodate various binding modes in a metastable equilibrium. $\mathrm{Ca}^{2+}$ may stabilize a given interface conformation (12). $\mathrm{Ca}^{2+}$-dependency of CaM binding differs among target proteins. While holo-CaM is strictly required for strong target binding in some cases, in others target interaction occurs preferentially at lower levels of occupancy by $\mathrm{Ca}^{2+}$. This accounts for the finding that CaM may be bound to many targets at resting $\mathrm{Ca}^{2+}$ concentrations $(8,12,22)$. At low $\mathrm{Ca}^{2+}$ the $\mathrm{N}$-lobe has higher stability than the C-lobe (23), which favors its binding in the apo form (pre-association) (8). On the other hand, due to its higher $\mathrm{Ca}^{2+}$ affinity, the C-lobe is more often involved in $\mathrm{Ca}^{2+}$-dependent target binding than the N-lobe $(12,24)$ and both the $\mathrm{N}$ - and C-lobes may participate to stabilize the protein-target complex (25).

$\mathrm{Ca}^{2+}$ binding changes $\mathrm{CaM}$ conformation to expose hydrophobic (methionine-rich) sites, either at the N-lobe or at the C-lobe, suitable to interact with hydrophobic residues in the anchor (18). The large size and flexibility of CaM interaction landscape is essential to accommodate a variety of "anchor" sidechains, thus providing $\mathrm{CaM}$ with its extraordinary pleiotropicity. Nonetheless, the observation that single site mutations may selectively affect CaM binding to a specific target suggests high specificity of the binding interface. Less information exists about the target binding mode of apo-CaM. The main differences with holo-CaM binding may concern the N-lobe and a larger involvement of electrostatic interactions (12).

Consistent with the notion that CaM lobes change their conformation when interacting with the target, the relationship between target and $\mathrm{Ca}^{2+}$ binding by $\mathrm{CaM}$ is mutual: binding to the target may increase CaM affinity for $\mathrm{Ca}^{2+}(12)$; this generates cooperativity in $\mathrm{Ca}^{2+}$-dependency of CaM-target interactions. According to modeling data (26), differences among targets in the extent of such cooperativity contribute to specificity of target recognition.

The third aspect of CaM signaling is modulation of target function which, depending on the target, can be either stimulatory or inhibitory. Target modulation can be either enacted by apo-CaM, or require $\mathrm{Ca}^{2+}$ binding and its mechanism differs among targets (see below examples for $\mathrm{RyR}$ and $\mathrm{Ca}_{\mathrm{v}} 1.2$ channels). As a general interpretational scheme, CaM binding may stabilize an otherwise short-lived configuration, spontaneously assumed by the target protein and associated with a specific functional state (12).

\section{"Free" and "Pre-Bound" CaM Pools}

Many CaM targets have been described so far. These include proteins involved in cell cycle, cell proliferation and autophagy (in healthy cells), tumor progression proteins (in cancerous cells) (5), proteins essential to cell communication and metabolism (27), and a wide number of ion channels (28-30). Most of these targets strictly require CaM pre-association to allow their regulation (31).

To better understand the role of CaM in cells, we need to consider its distribution between the "free" (cytosolic) and "prebound" pools. As mentioned previously, such a distribution may vary according to CaM's occupancy by $\mathrm{Ca}^{2+}(25)$.

Total CaM concentration is variable among tissues: it usually ranges between 5 and $40 \mu \mathrm{M}$ (e.g. ,about $6 \mu \mathrm{M}$ in intact myocytes) (32), but values up to $100 \mu \mathrm{M}$ have been described in specific cell types (e.g., in the testis) (33). In cardiomyocytes, even at diastolic $\mathrm{Ca}^{2+}$ concentration, $99 \%$ of total intracellular CaM is bound to cellular proteins, leaving about $50-100 \mathrm{nM}$ of free CaM (1\%) in the cell (32). Nonetheless, the proportion of CaM in the pre-bound pool is variable among tissue types (e.g., $11 \%$ in testis and $63 \%$ in spleen), and it may differ between normal and pathological cells and depend on environmental factors, such as cell density in culture (5). The pre-bound CaM pool includes mainly apo-CaM or CaM with incomplete occupancy, depending on the target (32); its functional relevance may be to increase speed of target response to local $\mathrm{Ca}^{2+}$ elevation.

The pre-bound CaM pool localizes to structures in the plasma membrane as well as in intracellular organelles; under resting $\mathrm{Ca}^{2+}$ concentrations (e.g., $100 \mathrm{nM}$ ), pre-bound CaM may largely exist as apo-CaM. Pre-bound apo-CaM may even be released to the free $\mathrm{CaM}$ pool in response to $\mathrm{Ca}^{2+}$ elevation, 
thus representing a local diffusible CaM store (22); this is true particularly in growing cells, where CaM is highly expressed.

As $\mathrm{Ca}^{2+}$ occupancy increases, CaM becomes almost completely bound to targets, thus leaving a very small pool of freely diffusible holo-CaM. Competition among targets for this pool may be of significance for their reciprocal regulation (32). Even if the CaM-target interaction is generally facilitated by $\mathrm{Ca}^{2+}$, the pattern is quite complex. Chin and Means (22) identified at least six CaM target groups, according to their $\mathrm{CaM}$ recognition sequences and $\mathrm{Ca}^{2+}$-dependency of binding. Some of them are strongly pre-bound to apo-CaM, for others binding is stronger for holo-CaM, while, finally, apo-CaM binding to a class of targets can be released by $\mathrm{Ca}^{2+}$, thus providing a local reservoir for free CaM.

\section{CAM MODULATION OF VOLTAGE-GATED CHANNELS}

\section{Voltage-Gated $\mathrm{Ca}^{2+}$ Channels $\left(\mathrm{Ca}_{\mathbf{v}} 1.2\right)$}

$\mathrm{Ca}^{2+}$ current from $\mathrm{Ca}_{\mathrm{v}} 1.2$ channels $\left(\mathrm{I}_{\mathrm{CaL}}\right)$ is the most abundant type in cardiomyocytes (34). The symbol "L" recapitulates the main features of this channel (as compared to other $\mathrm{Ca}^{2+}$ ones): large conductance, activation at larger depolarizations and long lasting openings. The activation of this channel is driven by the action potential upstroke, with $\mathrm{I}_{\mathrm{CaL}}$ reaching a peak in 2-7 ms. Thereafter, channels inactivate with time constants in the order of $50-100 \mathrm{~ms}$ at plateau potential, due to both $\mathrm{Ca}^{2+}$ and voltage-dependent gating (35). $\mathrm{Ca}^{2+}$ influx through $\mathrm{I}_{\mathrm{CaL}}$ leads to a rapid increase of cytosolic $\mathrm{Ca}^{2+}$ concentration in the confined space between the sarcolemmal and sarcoplamic reticulum (SR) membranes (also called "dyadic cleft"). This is responsible for the opening of ryanodine receptors (RyRs), $\mathrm{Ca}^{2+}$. activated $\mathrm{Ca}^{2+}$ channels clustered in the SR membrane facing $\mathrm{Ca}_{\mathrm{v}} 1.2$ channels.

$\mathrm{I}_{\mathrm{CaL}}$ is modulated by two feedback signals that, albeit of opposite sign, are both dependent on the rise of $\mathrm{Ca}^{2+}$ concentration close to cytosolic mouth of the channel and involve $\mathrm{CaM}$. $\mathrm{Ca}^{2+}$-dependent inactivation (CDI) is responsible for most of the rapid $\mathrm{I}_{\mathrm{CaL}}$ decay occurring during sustained depolarization (35). $\mathrm{Ca}^{2+}$-dependent facilitation (CDF), a weaker phenomenon, reflects instead the increase in $\mathrm{I}_{\mathrm{CaL}}$ peak conductance that may be observed during repetitive activation at high rates (36). Both $\mathrm{CDF}$ and $\mathrm{CDI}$ depend on $\mathrm{Ca}^{2+}$-CaM complexing (37). Earlier studies (37) reported that, whereas replacement of isoleucine or glutamine to alanine in the IQ motif of the C-terminal region of the $\mathrm{Ca}_{\mathrm{v}} 1.2$ channel $\alpha_{1 \mathrm{C}}$ subunit abolished CDI but enhanced CDF, replacement of isoleucine to glutamate in the same region abolished both forms of auto-regulation. This led to the conclusion that CDI and CDF had different mechanisms, but that CaM binding to the IQ motif is involved in both cases.

$\mathrm{Ca}_{\mathrm{v}} 1.2$ channels are constitutively associated with apo-CaM. Such pre-association is required since CaMs from the cytosolic bulk are unable to adequately access the binding site on $\mathrm{Ca}_{\mathrm{v}} 1.2$ during $\mathrm{Ca}^{2+}$ inflow (38); pre-association to the $\mathrm{C}$-terminal region of $\mathrm{Ca}_{\mathrm{v}} 1.2$ places $\mathrm{CaM}$ within a nanodomain at channel cytosolic mouth. This location confers to the C-lobe of pre-bound CaM the ability to sense $\mathrm{Ca}^{2+}$ changes in temporal relation to channel gating (14).

\section{Mechanism}

According to a recent interaction model, apo-CaM is constitutively tethered (pre-bound pool) to a pre-IQ motif present on the C-terminus of the $\alpha_{1 C}$ channel subunit. Such "pre-association" involves the $\mathrm{N}$-lobe and occurs at resting $\mathrm{Ca}^{2+}$ concentrations. Signaling activation by $\mathrm{Ca}^{2+}$ elevation (i.e., CDI induction) requires $\mathrm{Ca}^{2+}$ binding to the C-lobe, whose affinity for the target IQ motif is thus increased; C-lobe interaction with the IQ motif stabilizes the channel conformational state associated with CDI (8) (Figure 2). CDI has been further modeled as transitions between different states: apo-CaM release from the pre-association site, formation of the $\mathrm{Ca}^{2+}-\mathrm{CaM}$ complex, its subsequent binding to the effector site (14). The novel and most relevant feature of this model is that, using the difference in the kinetics of $\mathrm{Ca}^{2+}$ binding and unbinding between the $\mathrm{C}$ - and N-lobes (faster for the N-lobe), identifies their respective role in sensing $\mathrm{Ca}^{2+}$ at the channel mouth (local sensing, largely insensitive to intracellular $\mathrm{Ca}^{2+}$ buffering) vs. global cell $\mathrm{Ca}^{2+}$ (sensitive to even weak $\mathrm{Ca}^{2+}$ buffering). Unlike in neuronal channel isoforms, $\mathrm{Ca}_{\mathrm{v}} 1.2$ channels retain robust $\mathrm{CDI}$ even in the presence of strong $\mathrm{Ca}^{2+}$ buffering; such form of CDI is entirely triggered by $\mathrm{Ca}^{2+}$ association with the C-lobe (39). Numerical modeling provides the (counterintuitive) conclusion that, if associated with slow CaM-channel interaction kinetics, fast $\mathrm{Ca}^{2+}$ binding/unbinding (typical of the N-lobe) may best support selective sensing of a smaller but sustained $\mathrm{Ca}^{2+}$ signal (14). The latter is typical of CDI in non-cardiac channel isoforms (39).

\section{CDF Mechanism}

As discussed above, earlier studies indicated that CDF requires an intact anchoring region on the channel C-terminus, thus suggesting that pre-bound $\mathrm{CaM}$ is involved (37). Nonetheless, there is now general agreement that, unlike CDI, CDF is operated by $\mathrm{Ca}^{2+}$-CaM dependent activation of calmodulinkinase II (CaMKII), which then phosphorylates the $\mathrm{Ca}_{\mathrm{v}} 1.2$ channel at two serine residues close to the EF-hand motif (40) (Figure 2); mutation of these two serine residues abolished CDF but did significantly affect CDI (40), hence confirming independent mechanisms for these processes. Notably, CaMKII phosphorylation of nearby serine residues also induces Mode2 gating of the channel (41). Thus, at variance with CDI, CDF is the consequence of protein phosphorylation, dependent on CaM, but not directly operated by it.

\section{Voltage-Gated $\mathrm{K}^{+}$Channels $\left(\mathrm{K}_{\mathrm{v}} \mathbf{7 . 1}\right)$}

$\mathrm{K}_{\mathrm{v}} 7.1$ is a $\mathrm{K}^{+}$-selective channel which, in association with KCNE subunits, carries the slow component of the delayed-rectifier current $\left(\mathrm{I}_{\mathrm{Ks}}\right)$. $\mathrm{I}_{\mathrm{Ks}}$ gating is positively regulated by cytosolic $\mathrm{Ca}^{2+}$ through a CaM-dependent process (42), with an effect similar to that of the membrane constituent phosphatidylinositol-4,5bisphosphate (PIP2). Indeed, PIP2 and the N-lobe of CaM competitively interact at the same site on the $\mathrm{K}_{\mathrm{v}} 7.1$ protein (the helix B on the proximal C terminus). Interpretation of the 


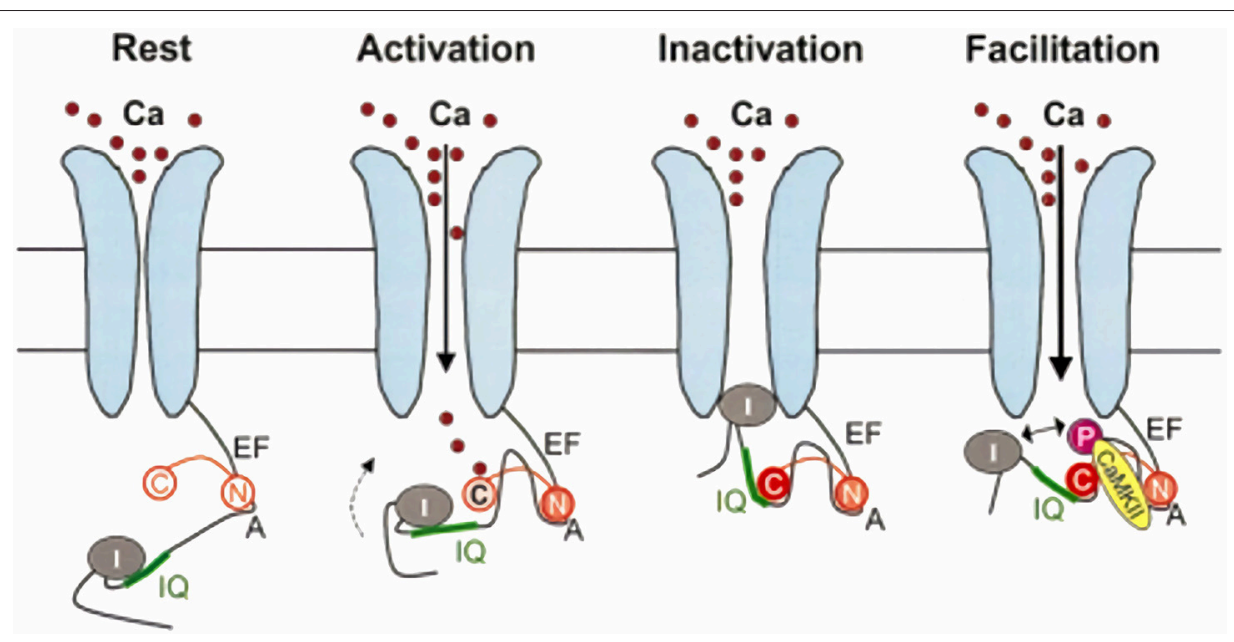

FIGURE 2 | Model for CaM-dependent modulation of Cav1.2 channels (l $\left.\mathrm{CaL}_{\mathrm{L}}\right)$. CDI mechanism: in the channel closed state (Rest), the $\mathrm{N}$-lobe of apo-CaM ( $\left.\mathrm{N}\right)$ is constitutively bound to a pre-IQ region $(\mathrm{A})$ in the channel $\mathrm{C}$-terminus. When the channel opens (Activation), the CaM $\mathrm{C}$-lobe $(\mathrm{C})$ binds to the entering $\mathrm{Ca}{ }^{2+}$, which increases its affinity for the channel IQ-domain; this moves the channel inactivation particle (I) in the permeation path (Inactivation). CDF mechanism: holo-CaM binding to CaMKII promotes channel phosphorylation, which results in repulsion of the inactivation particle from the permeation pore (Facilitation). Modified from Maier and Bers (8).

effect of a helix B $\mathrm{K}_{\mathrm{v}} 7.1$ mutant (K526E) and of interference of $\mathrm{Ca}^{2+}{ }_{-} \mathrm{CaM}$ with $\mathrm{K}_{\mathrm{V}} 7.1$ pull-down by PIP2 has led to the following model: at diastolic $\mathrm{Ca}^{2+}$ levels, $\mathrm{CaM}$ is bound to a non-activating $\mathrm{K}_{\mathrm{V}} 7.1$ site (helix $\mathrm{A}$ ) by its apo-C-lobe; the $\mathrm{N}$-lobe is displaced from the helix $\mathrm{B}$ site. As cytosolic $\mathrm{Ca}^{2+}$ increases, calcification of the C-lobe causes its dissociation from helix $\mathrm{A}$ and the $\mathrm{N}$-lobe then interacts with its site on the helix $\mathrm{B}$; this results in stabilization of the channel open state (43). According to an alternative model, at resting $\mathrm{Ca}^{2+}$ levels the $\mathrm{C}$ - and N-lobes are permanently bound to the channel (at helices $\mathrm{A}$ and $\mathrm{B}$, respectively) and limit its open probability; when $\mathrm{Ca}^{2+}$ increases, $\mathrm{N}$-lobe binding is reinforced and C-lobe is released thereby relieving the inhibitory effect on channel gating (44).

Both models imply that CaM binding to $K_{\mathrm{V}} 7.1$ and positive regulation of $\mathrm{I}_{\mathrm{Ks}}$ are separate processes. Binding occurs in the apo-CaM form (pre-bound pool), $\mathrm{I}_{\mathrm{Ks}}$ enhancement requires $\mathrm{Ca}^{2+}$ elevation. Furthermore, both CaM lobes are involved and a preserved C-lobe $\mathrm{Ca}^{2+}$ affinity is essential for the signaling function.

PIP2 is a membrane phospholipid degraded by phospholipase C (PLC) to produce inositol 3-phosphate (IP3) in response to activation of a number of membrane receptors associated with $\mathrm{G}_{\mathrm{q}}$ proteins. Receptor activation may result in PIP2 depletion, which would reduce $\mathrm{I}_{\mathrm{Ks}}$; however, IP3-induced $\mathrm{Ca}^{2+}$ release from the sarcoplasmic reticulum may compensate PIP2 reduction by activating positive $\mathrm{I}_{\mathrm{Ks}}$ regulation by $\mathrm{Ca}^{2+}{ }_{-} \mathrm{CaM}$. This may represent the main physiological role of $\mathrm{I}_{\mathrm{Ks}}$ modulation by $\mathrm{Ca}^{2+}$ CaM, which would therefore be of particular relevance during activation of the PLC-IP3 signaling pathway.

$\mathrm{CaM}$ integrity may also be necessary for $\mathrm{K}_{\mathrm{v}} 7.1$ channel trafficking; indeed, mutations disrupting $\mathrm{N}$ - and C-lobe integrity reduce channel membrane expression (44).
It has been reported that holo-CaM complexing with KCNE4 (channel $\beta$-subunit) inhibits $\mathrm{I}_{\mathrm{Ks}}(45)$. While this would provide antagonism to direct holo-CaM modulation of the channel $\alpha$-subunit, the physiological role of CaM-KCNE4 interaction remains unclear.

CaM-mediated $\mathrm{I}_{\mathrm{Ks}}$ regulation also occurs indirectly by CaMKII-mediated phosphorylation of the channel at serine 484; contrary to direct CaM modulation, phosphorylative modulation is inhibitory and may account for $\mathrm{I}_{\mathrm{Ks}}$ downregulation upon sustained $\beta$-adrenergic receptor activation (46).

\section{Voltage-Gated $\mathrm{Na}^{+}$Channels $\left(\mathrm{Na}_{\mathrm{v}} \mathrm{1.5}\right)$}

Among all voltage-gated channels involved in arrhythmogenesis, $\mathrm{Na}_{\mathrm{v}} 1.5$ channels also interact with CaM. CaM binds to an IQ motif on the $\mathrm{C}$-terminus of this channel in a $\mathrm{Ca}^{2+}$-independent manner. Binding reduces CaM's affinity for $\mathrm{Ca}^{2+}$ and does not induce the conformational changes that have been observed for $\mathrm{Ca}_{\mathrm{v}} 1.2$ channels; therefore, similarities in the binding site may not necessarily translate into similarities of channel modulation. Nonetheless, disruption of the CaM binding site (by mutation of the $\mathrm{Na}_{\mathrm{v}} 1.5$ IQ motif) leads to the enhancement of persistent $\mathrm{Na}^{+}$current, thus suggesting a role of CaM in stabilizing the inactivated state (47), possibly by fostering the interaction between the channel C-terminus and the II-IV linker. According to another model, $\mathrm{CaM}$ binding to $\mathrm{Na}_{\mathrm{v}} 1.5$ channels would obstruct their direct modulation by $\mathrm{Ca}^{2+}$; holo-CaM would lose its affinity for the channel, thus unveiling the direct modulatory site (48). In this case, failure of CaM interaction with the channel (as in the case of holo-CaM) causes a "leftward" (negative) shift of the steady-state inactivation curve (48); this would presumably reduce channel availability at diastolic potential as well as the "window" component of $\mathrm{I}_{\mathrm{Na}}$. 
Overall, while CaM interaction with $\mathrm{Na}_{\mathrm{v}}$ and $\mathrm{Ca}_{\mathrm{v}}$ channels are somewhat similar, the consequences of CaM-dependent modulation on $\mathrm{Na}_{\mathrm{v}}$ function are less defined and, possibly, quantitatively less important.

\section{RYRS MODULATION BY $\mathrm{Ca}^{2+}$ AND $\mathrm{Ca}^{2+}-\mathrm{CAM}$}

RyRs are homotetramers of $\sim 2,200 \mathrm{kDa}$ (each subunit is $>550$ $\mathrm{kDa}$ ), containing $\sim 5,035$ amino acid residues in total, sharing the general structure of the six-transmembrane ion channel superfamily (49). Since RyRs span the SR membrane, they have domains facing both the cytosol and the SR lumen. Of the three isoforms present in nature, RyR2 is the predominant one in cardiac myocytes, where it is organized in large clusters on the SR membrane (50). In T-tubules, RyR2 clusters are separated from sarcolemmal $\mathrm{Ca}_{\mathrm{v}} 1.2$ channels by a $10-15 \mathrm{~nm}$ gap; thus, small $\mathrm{Ca}^{2+}$ influx through $\mathrm{I}_{\mathrm{CaL}}$ exposes them to very high $\mathrm{Ca}^{2+}$ concentrations $(50,51)$. This structural arrangement is generally referred to as "couplon" (52). The $\mathrm{RyR} / \mathrm{Ca}_{\mathrm{v}}$ ratio in couplons is up to 15-fold higher in cardiac than in skeletal muscle and differs between species (53).

RyRs are strongly regulated by $\mathrm{Ca}^{2+}$ in CaM-independent ways. At the same time, they are regulated by CaM in both $\mathrm{Ca}^{2+}$. dependent and -independent ways. This makes investigation of CaM's role in RyRs' regulation very complex.

\section{CaM-Independent RyR Regulation by $\mathrm{Ca}^{2+}$}

RyR gating is highly sensitive to $\mathrm{Ca}^{2+}$ on both sides of the SR membrane in a CaM-independent way. Although not the focus of the present review, a brief discussion of such "direct" regulation by $\mathrm{Ca}^{2+}$ is required to understand the potential difficulty in isolating the CaM-dependent one.

Each of the $\mathrm{N}$ - and C-terminal domains of RyR2 contains two EF-hand $\mathrm{Ca}^{2+}$ binding motifs (54), similar to those of CaM. These motifs are both on the cytosolic domain of RyR2; they show high (C-terminal) and low (N-terminal) affinity for $\mathrm{Ca}^{2+}$ and induce channel opening and inactivation, respectively $(55,56)$. Since RyR2 inactivation occurs at $\mathrm{Ca}^{2+}$ concentrations exceeding the physiological range, $\mathrm{Ca}^{2+}$-dependent activation is the dominant phenomenon and the basis for the $\mathrm{Ca}^{2+}$-induced$\mathrm{Ca}^{2+}$ release (CICR) mechanism (7).

SR luminal $\mathrm{Ca}^{2+}$ modulates $\mathrm{RyR} 2$ open probability by two CaM-independent mechanisms. The indirect one involves stabilization of the closed state by a macromolecular complex, involving calsequestrin (CASQ) and is disrupted by increases in luminal $\mathrm{Ca}^{2+}$ (57). Sensitivity to luminal $\mathrm{Ca}^{2+}$ is preserved after CASQ knock out. This stands for the presence of a $\mathrm{Ca}^{2+}$-sensing mechanism on the RyR protein itself, located in a luminal domain also involved in control of $\mathrm{Ca}^{2+}$ permeation (58). Direct lumenal $\mathrm{Ca}^{2+}$ sensing may be important for channel activation under conditions of SR overload (59).

\section{CaM-Dependent RyR Regulation}

CaM-dependent modulation of RyRs differs between channel isoforms, which have only $\sim 70 \%$ of gene homology and contain three divergent regions (60). In general, conductance of all the three RyR isoforms is reduced by $\mathrm{CaM}$ when cytosolic $\mathrm{Ca}^{2+}$ is above $1 \mu \mathrm{M}$. At lower $\mathrm{Ca}^{2+}$ concentrations, favoring apo$\mathrm{CaM}$ and more relevant to diastole, $\mathrm{CaM}$ increases the open probability of RyR1 and RyR3 $(61,62)$, but it stabilizes the closed conformation of RyR2 (54).

RyR2 channels have high affinity (nanomolar $\mathrm{K}_{\mathrm{d}}$ ) for both apo-CaM and holo-CaM, thus resulting in a pre-bound CaM pool $(54,63)$. Apo-CaM may actually be a stronger inhibitor of RyR2 opening than holo-CaM, as indicated by relief of inhibition at $\mathrm{Ca}^{2+}$ concentrations in the $\mu \mathrm{M}$ range (64). Therefore, CaM modulation of RyR2 gating may be largely $\mathrm{Ca}^{2+}$-independent. Increasing $\mathrm{Ca}^{2+}$ up to $100 \mu \mathrm{M}$ has been reported to increase the number of CaM molecules bound to RyR2 (from 1 to 7.5 per RyR2 tetramer) (54); however, it is difficult to relate responses to such an abnormally high $\mathrm{Ca}^{2+}$ concentration to physiological function.

Given that CaM binding domains are highly homologous between RyR1 and RyR2 (65), what may explain the $\mathrm{Ca}^{2+}$ dependent discrepancy of CaM effects on RyR opening between RyR1 and RyR2 channels?

Mutations in both the N-terminal and central RyR2 regions similarly destabilize the channel closed state; this suggests that the latter may require interaction between these two regions ("zipping" model of RyR gating). This view is confirmed by the effect of peptides (e.g., DPc-10) interfering with such interaction (66). On the other hand, CaM binds to a domain other than those involved in zipping. According to the "inter-domain hypothesis," CaM binding to RyR2 may induce a protein conformation change that allosterically stabilizes the zipping interaction (and the closed state) (Figure 3). Vice versa, agents interfering with the zipping interaction may reduce CaM binding affinity (66).

A different gating model has been proposed for RyR1 channels, in which the channel CaM binding domain is followed, within about 450 residues, by a CaM-like sequence. FRET data indicate that, at high $\mathrm{Ca}^{2+}$, the two channel domains interact with each other in the folded protein; such $\mathrm{Ca}^{2+}$-dependent interaction is required for channel opening. Binding of holo$\mathrm{CaM}$ to the channel may disrupt the activating interdomain interaction, thus explaining CaM-induced RyR1 inhibition at high $\mathrm{Ca}^{2+}$ concentrations (68). However, this model does not explain why low $\mathrm{Ca}^{2+}$ concentrations (favoring apo-CaM) may produce CaM-dependent RyR1 activation, which remains an open question.

Cryo-EM studies in RyR1 indicate that increasing $\mathrm{Ca}^{2+}$ shifts CaM binding to the channel by about $3 \mathrm{nM}$, corresponding in the $3 \mathrm{D}$ structure to two different protein domains. In view of the fact that CaM activates RyR1 at low $\mathrm{Ca}^{2+}$ and inhibits it at high $\mathrm{Ca}^{2+}$, the two domains may be seen as activator and inhibitory sites, respectively. Importantly, these studies indicate that the $\mathrm{Ca}^{2+}$-dependent shift in CaM binding site is a consequence of a rearrangement of the binding surface of CaM, rather than of RyR1 conformation (69) (which is also $\mathrm{Ca}^{2+}$-dependent). The same technique shows that in RyR2 CaM binds to the "inhibitory site" (as identified in RyR1) already at low $\mathrm{Ca}^{2+}$; this might explain why RyR2 is inhibited by CaM in a $\mathrm{Ca}^{2+}$-independent way (69). Apparently at odd with these observations, FRET experiments (in the same study), measuring the position of CaM 


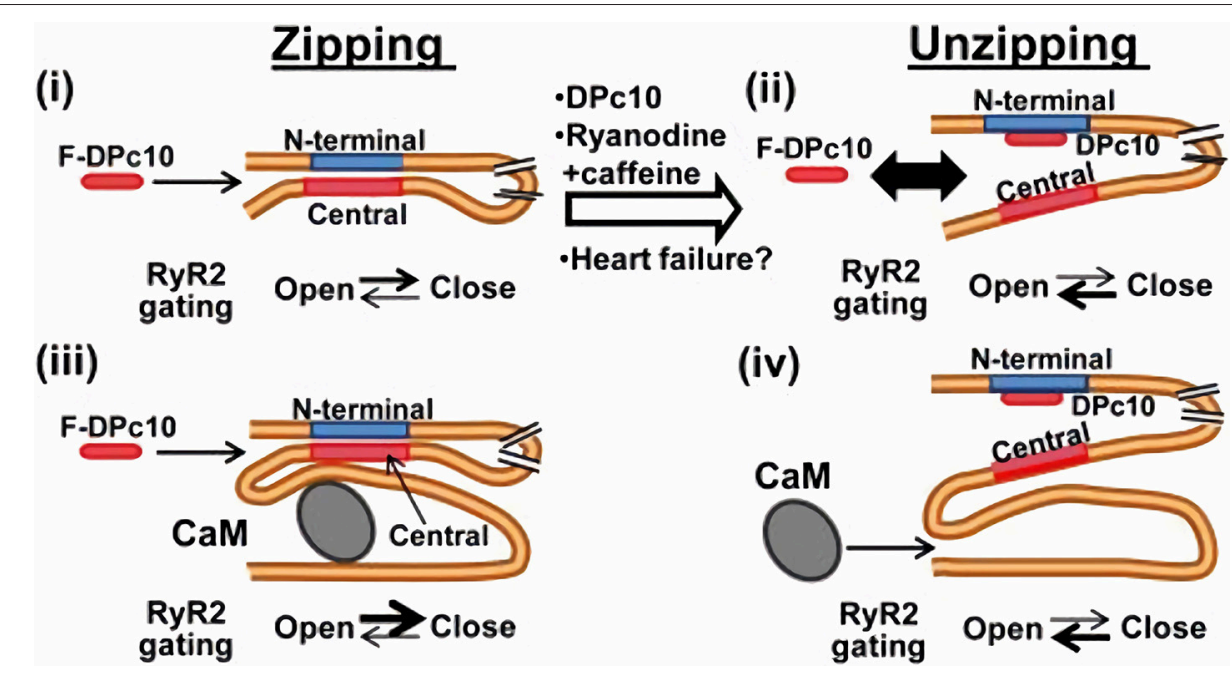

FIGURE 3 | CaM-dependent modulation of RyR2 channels. RyR2 closed state is stabilized by the interaction (zipping) between "terminal" and "central" regions of the $\mathrm{N}$-terminal (cytosolic) tail of the protein. If such interaction is removed (unzipping), the channel closed state is destabilized. Apo-CaM binds to a domain distal to the "zipping" one, but the resulting conformation allosterically facilitates the zipping interaction, thus stabilizing RyR2 closed state. CaM and F-DPc10 (a peptide obstructing the zipping interaction) allosterically "compete" for binding to RyR2. Similarly, the unzipped state, promoted by drugs and reactive oxygen species which facilitate RyR2 opening, reduces RyR2 affinity for CaM (67). F-DPc10 is a peptide fragment designed to prevent the interaction between the central and N-terminal protein domains (a tool in testing the unzipping model). From Oda et al. (66).

relative to that of FKBP in RyR1, did not detect $\mathrm{Ca}^{2+}$-dependent shifts in CaM position of a magnitude compatible with the results of cryo-EM data (69). However, $\mathrm{Ca}^{2+}$-induced structural changes in both probe-carrying proteins are possible and might minimize FRET distances even in the presence of real shifts in binding position.

In conclusion, even if the detailed mechanism remains to be resolved, it is now accepted that direct regulation of RyR gating by $\mathrm{CaM}$ is $\mathrm{Ca}^{2+}$-dependent (stimulatory to inhibitory) in RyR1 and $\mathrm{Ca}^{2+}$-independent (always inhibitory) in RyR2. Formation of the $\mathrm{Ca}^{2+}$-CaM complex does affect RyR2 gating significantly, but this occurs through an indirect mechanism, involving CaMKII activation.

CaMKII is a cytosolic serine-threonine kinase activated by $\mathrm{Ca}^{2+}$ with a $\mathrm{K}_{\mathrm{d}}$ of 20-100 nM, which dramatically decreases (to $60 \mathrm{pM}$ ) after enzyme autophosphorylation (8). The $\mathrm{Ca}^{2+}$ CaM complex activates kinase activity by binding to an enzyme regulatory region, located in the central protein domain. Enzyme activation occurs by displacement of an auto-inhibitory segment that occludes access of the substrate to the N-terminal catalytic domain. As for other targets, both $\mathrm{N}$ - and C-terminal CaM lobes are involved in activation of kinase activity (25), which is in this case strictly $\mathrm{Ca}^{2+}$-dependent.

CaMKII mediates a number of $\mathrm{Ca}^{2+}$-activated phosphorylations, including that of RyR2 at Ser2814 on the cytosolic surface of the channel (exclusively for CaMKII) and, additional serine residues $(49,70)$. Most of the evidence converges to show that CaMKII-dependent phosphorylation facilitates opening of RyR2 channels, thus increasing sensitivity of SR $\mathrm{Ca}^{2+}$-release to cytosolic $\mathrm{Ca}^{2+}$. This may be particularly relevant under pathological conditions (70).
CaM binding to RyRs also depends on factors other than $\mathrm{Ca}^{2+}$, such as $\mathrm{pH}, \mathrm{Mg}^{2+}$ oxidation state $(54,62)$. In particular, oxidative modifications compromise the normal activity of RyR2 by influencing their luminal $\mathrm{Ca}^{2+}$ regulation in a manner similar to that observed in heart failure (71).

Stabilization of RyR2 closed state by CaM is crucial in minimizing spontaneous (non-triggered) $\mathrm{Ca}^{2+}$ release from the SR in the form of either "Ca-leak" (random release from individual RyRs) or "Ca ${ }^{2+}$ spark" (synchronous release from a RyR2 cluster), a function pivotal to both contractile and electrical function of cardiomyocytes (63).

\section{PHENOTYPES IN CAM MUTATIONS AND UNDERLYING MECHANISMS}

Mutations in one of the three CALM genes, even in the heterozygous form, have been described in patients with a severe cardiac phenotype, characterized by a high propensity to ventricular arrhythmias, syncopal episodes and sudden death at a young age (72).

Despite sharing strong electrical instability, two distinct phenotypes can be identified in carriers of CaM mutations: the long QT syndrome (LQTS) (9, 73), characterized by prolongation of repolarization, and catecholamine-induced ventricular tachycardia (CPVT), characterized instead by exercise-induced ventricular arrhythmias (74). In general, each specific CALM mutation is associated with one of the two phenotypes; nonetheless, mutations with mixed phenotypes have also been described (72). Such confounding complexity contrasts with an apparently sharp separation of the molecular mechanisms underlying the LQTS and CPVT patterns. A third, 
less well-defined arrhythmia phenotype, idiopathic ventricular fibrillation (IVF), has also been associated with a CALM mutation (75) and will be addressed here in paragraph Mixed phenotype.

A point of interest in the interpretation of CALM mutations is their extremely high penetrance: 1 mutant allele in 6 encoding for the same amino acid sequence (as in heterozygous mutations) is sufficient to result in marked functional derangements.

Also in view of the multiplicity of functions exerted by CaM in many cell types, all this suggests that, for one reason or another, mutant CaMs must interact with their target with high specificity. In the following paragraphs we will describe the cellular functional derangements associated with the LQTS and CPVT phenotypes and address, as much as current knowledge allows, the mechanisms underlying target specificity of CaM mutations.

\section{LQTS Phenotype}

Prolongation of action potential duration (APD), reflected as QT interval prolongation on the ECG, can result from loss of function of outward currents, or gain of function of inward ones; therefore, CaM abnormalities affecting modulation of $\mathrm{K}_{\mathrm{v}} 7.1\left(\mathrm{I}_{\mathrm{Ks}}\right)$ and $\mathrm{Ca}_{\mathrm{v}} 1.2\left(\mathrm{I}_{\mathrm{CaL}}\right)$ might theoretically be involved in prolongation of repolarization. Enhancement of the "window" $\left(\mathrm{I}_{\mathrm{NaW}}\right)$ or "late" ( $\left.\mathrm{I}_{\mathrm{NaL}}\right)$ components of the $\mathrm{Na}^{+}$current $\mathrm{I}_{\mathrm{Na}}\left(\mathrm{Na}_{\mathrm{v}} 1.5\right.$ channel) might represent a further potential mechanism.

Nevertheless, gain of $\mathrm{Ca}_{\mathrm{v}} 1.2$ function ( $\mathrm{I}_{\mathrm{CaL}}$ enhancement) has emerged as the dominant mechanism in CALM gene mutations associated with delayed repolarization.

In 2013, Crotti et al. reported three de novo heterozygous missense CALM gene mutations in LQT-infants with recurrent cardiac arrest (73). In particular, the CALM1-p.D130G and CALM2-p.D96V mutations affect highly conserved aspartic acid residues (C-lobe EF IV and EF III, respectively) involved in $\mathrm{Ca}^{2+}$ binding. The CALM1-p.F142L (next to C-lobe EF IV), albeit outside the EF-hand, is expected to alter the energetics of the conformational change associated to $\mathrm{Ca}^{2+}$ binding (22). The p.D130G mutation, associated with the LQTS phenotype, has also been identified in the CALM3 gene (76), thus reinforcing the concept that mutation effect may be independent of the gene affected. In vitro $\mathrm{Ca}^{2+}$ binding studies revealed that all these three mutations are characterized by a 5 - to 50 -fold reduction in $\mathrm{Ca}^{2+}$ binding affinity of the C-lobe, without affecting N-lobe affinity (73). Overexpression of these mutations in guinea-pig myocytes or an engineered cell line showed loss of $\mathrm{I}_{\mathrm{CaL}} \mathrm{CDI}$, leading to action potential prolongation with enhanced intercellular variability. The amplitude of $\mathrm{Ca}^{2+}$ transients and its dispersion were also increased, likely secondary to increased $\mathrm{Ca}^{2+}$ influx; notably, spontaneous $\mathrm{Ca}^{2+}$ release events were not reported (77). Indeed, consistent with the LQTS phenotype, RyR2 function was unaffected. Binding of CaM mutants to $\mathrm{Ca}_{\mathrm{v}} 1.2$ was tested by FRET and found to be enhanced for p.F142L and unaffected by the other mutations. On the other hand, titration of WT vs. mutant expression levels showed that a ratio (WT/mutant) of 7 (compatible with heterozygosity) was enough to impair CDI (77). Therefore, selectivity of mutant CaMs in altering $\mathrm{Ca}_{\mathrm{v}} 1.2$ channel function can be explained by the fact that modulation of this target requires a pre-bound apo-CaM pool (containing mixtures of WT and mutant CaMs) and subsequent $\mathrm{Ca}^{2+}$ binding to this pool (impaired in mutants by loss of $\mathrm{Ca}^{2+}$ affinity). This interpretation would explain sparing of RyR2, whose modulation may not require $\mathrm{Ca}^{2+}$ binding, and of CaMKII, which binds $\mathrm{CaM}$ directly in its holo-form (not represented if $\mathrm{Ca}^{2+}$ affinity is reduced). Selective CDI impairment by additional mutations reducing C-lobe $\mathrm{Ca}^{2+}$ affinity (CALM2-p.D132H and CALM1p.D132V) has also been reported in transfection studies on human induced pluripotent stem cell-derived cardiomyocytes (78).

Other heterozygous LQTS mutations, CALM2-p.D130V and CALM1-p.E141G have been recently identified by Boczek et al. (79). As in p.D130G, the former involves replacement of aspartic acid by a neutral residue; therefore, loss of C-lobe $\mathrm{Ca}^{2+}$ affinity is to be expected. CALM1-p.E141G has a phenotype closely resembling that of CALM1-p.F142L, indicating that residues 141 and 142 are both crucial for C-lobe $\mathrm{Ca}^{2+}$ binding. Notably, when transfected in isolation, CALM1-p.E141G also enhanced $\mathrm{I}_{\mathrm{NaL}}$, but the effect disappeared when mutant and WT constructs were coexpressed. This is consistent with a role of CaM stabilizing $\mathrm{Na}_{\mathrm{v}} 1.5$ inactivation (see above) and implies lack of functional dominance of the mutation for this target. However, at least according to a current model of CaM-Na 1.5 interaction (48), reduced affinity of mutant $\mathrm{CaM}$ for $\mathrm{Ca}^{2+}$ would not explain $\mathrm{I}_{\mathrm{NaL}}$ enhancement.

CaM mutations resulting in downregulation of $\mathrm{K}^{+}$currents have not been reported, even if $\mathrm{I}_{\mathrm{Ks}}$ function has been tested in some cases (CALM1-p.F142L) (80). Nonetheless, the $\mathrm{K}_{\mathrm{v}} 7.1$ $\alpha$-subunit mutation p.K526E, accounting for a case of LQT1, impairs interaction of the channel's helix B with CaM's N-lobe. This leads to $\mathrm{I}_{\mathrm{Ks}}$ downregulation and delayed repolarization (43). Considering that the mode of $\mathrm{CaM}-\mathrm{K}_{\mathrm{v}} 7.1$ interaction involves a pre-bound pool and $\mathrm{Ca}^{2+}$-dependent C-lobe signaling (as for $\mathrm{Ca}_{\mathrm{V}} 1.2$ ), it is surprising that CaM mutations with loss of Clobe $\mathrm{Ca}^{2+}$ affinity may not affect $\mathrm{I}_{\mathrm{Ks}}$. One tentative explanation is compensation of the loss of CaM-dependent regulation by PIP2 signaling; it would be therefore interesting to evaluate the effect of known CaM mutations on $\mathrm{I}_{\mathrm{Ks}}$ under conditions of PIP2 depletion.

\section{CPVT Phenotype}

Catecholaminergic polymorphic ventricular tachycardias are malignant arrhythmias with an ECG pattern suggesting multifocal origin (unlike TdP), typically induced by exercise, or other conditions associated with enhanced adrenergic stimulation (81). The prototypical form of this arrhythmia has been associated with mutations of RyR2 channels, or of the proteins associated with them in a macromolecular complex (junction, triadin, calsequestrin, sorcin etc.). The electrical disturbance at the basis of CPVT originates from " $\mathrm{Ca}^{2+}$ waves," i.e., macroscopic surges of cytosolic $\mathrm{Ca}^{2+}$ resulting from spontaneous RyR opening at a point site, followed by auto-regenerative propagation (by $\mathrm{Ca}^{2+}$-induced $\mathrm{Ca}^{2+}$ release) of the ionic perturbation to the whole cell (82). The mechanism connecting the $\mathrm{Ca}^{2+}$ wave to membrane potential is $\mathrm{Ca}^{2+}$ induced activation of the electrogenic $\mathrm{Na}^{+} / \mathrm{Ca}^{2+}$ exchanger (NCX), which results in a depolarizing current, also referred 
to as "transient inward current" $\left(\mathrm{I}_{\mathrm{TI}}\right)$. While " $\mathrm{Ca}^{2+}$ overload" facilitates $\mathrm{Ca}^{2+}$ waves (by increasing RyRs open probability), it is neither necessary nor sufficient to induce them; indeed some degree of intrinsic RyR2 instability may be involved even in the prototypical case of digitalis toxicity (83).

CaM mutations associated with the CPVT phenotype are generally characterized by a relatively small impairment of C-lobe $\mathrm{Ca}^{2+}$ binding (e.g., CALM1-p.N98S, CALM1-p.N54I, and CALM3-p.A103V) $(84,85)$, which (as shown for CALM3p.A103V) (85) corresponds to a minor effect on $\mathrm{I}_{\mathrm{CaL}}$ CDI. Besides this, the relationship between mutation features and the CPVT phenotype is somewhat elusive. Nyegaard and colleagues tested CALM1-p.N54I and -p.N98S binding to a small RyR2 segment, found a decrease in CALM1-p.N98S affinity only at low $\mathrm{Ca}^{2+}$ levels and explained mutation phenotype with loss of CaM-RyR2 complexing. These findings were later contradicted by studies using the entire RyR2 protein (86), that detected an increase in RyR2 affinity for both these mutations (also accounting for dominance of effects). Nonetheless, increased affinity for RyR2 may not be a prerequisite for channel destabilization; indeed the CPVT mutation CALM3-p.A103V, which strongly increased $\mathrm{Ca}^{2+}$ release events, displayed normal RyR2 affinity (85). Notably, mutations sites N54 and N98, albeit affecting the $\mathrm{N}$ - and C-lobes, respectively, are not contained within any known protein-protein interaction sites (84).

In conclusion, the features of CPVT mutations may explain why they are not generally associated with an LQTS phenotype (however see below), but a general mechanism by which they induce RyR2 instability cannot be clearly envisioned. Since CaM interaction with RyR2 is essentially $\mathrm{Ca}^{2+}$-independent, the mechanism must conceivably reside in a change of $3 \mathrm{D}$ protein conformations involved in CaM-RyR2 complexing; nonetheless, the nature of this change remains to be clarified.

\section{Mixed Phenotype}

Notwithstanding the apparently sharp demarcation of CaM abnormalities affecting $\mathrm{Ca}_{\mathrm{v}} 1.2$ and RyR2 channels, several mutations have been associated with both LQTS and CPVT phenotypes. CaM mutations were found in five subjects with QT prolongation; nonetheless, two of them (CALM2-p.D132E and -p.Q136P) were associated with arrhythmia features strongly suggestive of SR instability and thus were assigned to the CPVT phenotype (72). These mutations affect EF III and EF IV of the C-loop and displayed reduced $\mathrm{Ca}^{2+}$ affinity; thus, even if $\mathrm{I}_{\mathrm{CaL}} \mathrm{CDI}$ was not directly tested in this study, it may be tentatively considered responsible for the observed QT prolongation. Intriguingly, two different reports assign LQTS and CPVT phenotypes to the same mutation (p.N98S) occurring in genes CALM2 (72) and CALM (84), respectively; since the CaM amino acid sequence encoded by the 2 genes is identical, other factors should account for the discrepancy.

The reason for SR instability in all these cases is as elusive as the properties of mutations that favor RyR2 dysfunction (see above). Nonetheless, it should be considered that impairment of $\mathrm{I}_{\mathrm{CaL}} \mathrm{CDI}$ and the resulting $\mathrm{APD}$ prolongation are obviously stress conditions for intracellular $\mathrm{Ca}^{2+}$ homeostasis, requiring robust compensatory mechanisms. Thus, albeit not observed in
hiPSC-CMs from an LQTS case (80), SR instability secondary to defective CDI might occur in subjects (or conditions) in which such compensation is less efficient. Thus, assignment to an LQTS or CPVT clinical phenotype may not be always accurate in defining the mutation-induced abnormality accounting for arrhythmogenesis.

Marsman et al. have described the CALM1-p.F90L mutation in a patient with IVF, i.e., VF episodes without the features of either LQTS or CPVT (mild QT prolongation only during exercise recovery) (75). The mutation, which resides on the linker between EF III and EF IV, impairs C-lobe $\mathrm{Ca}^{2+}$ affinity conformational stability and CaM-RyR2 interaction (87). In heterologous expression experiments, p.F90L also affects small-conductance $\mathrm{Ca}^{2+}$-activated $\mathrm{K}^{+}$channels (SK channels) (88); nonetheless, the role of these channels in ventricular electrophysiology is unclear.

\section{EVALUATING CAM MUTATIONS IN PATIENT-DERIVED CARDIOMYOCYTES}

Induced pluripotent stem cell-derived cardiomyocytes from mutation carriers (hiPSC-CMs) provide the means to test mutation effects in the context of each patient's genetic background. Recent studies have exploited this cellular model to test the effect of CaM mutations. Yamamoto et al. reported a typical LQTS phenotype for the heterozygous CALM2-p.N98S mutation and obtained reversal of the phenotype by knocking out the mutant allele by gene editing (89), thus supporting a causal relationship between mutation and phenotype. Notably, CALM2p.N98S affinity for $\mathrm{Ca}^{2+}$ is only mildly reduced, and a CPVT phenotype has also been reported for this mutation (84).

We recently investigated hiPSC-CMs from a patient with LQTS phenotype and heterozygous carrier of the CALM1p.F142L mutation (80) (Figure 4). CDI of $\mathrm{I}_{\mathrm{CaL}}$ was severely impaired, thus accounting for APD prolongation (which was reversed by $\mathrm{I}_{\mathrm{CaL}}$ blockade) and its failure to shorten adequately at high pacing rates. As expected from the increase in $\mathrm{Ca}^{2+}$ influx, the amplitude of $\mathrm{V}$-triggered $\mathrm{Ca}^{2+}$ transients was significantly increased; nonetheless, SR $\mathrm{Ca}^{2+}$ content was normal and no spontaneous $\mathrm{Ca}^{2+}$ release events were observed, thus suggesting preserved homeostatsis of intracellular $\mathrm{Ca}^{2+}$. This argues against SR instability as the arrhythmogenic mechanism in this case and suggests a primary role of prolonged and "stiff" (non-rateadaptive) repolarization instead (80). Other currents under CaM modulation were also evaluated in this study: $\mathrm{I}_{\mathrm{Ks}}$ was found to be unaffected and a persistent component of $\mathrm{I}_{\mathrm{Na}}$ (likely contributed by $\mathrm{I}_{\mathrm{NaW}}$ ) was significantly reduced (80). While this confirms loss of $\mathrm{I}_{\mathrm{CaL}} \mathrm{CDI}$ as the sole mechanism of repolarization abnormality, $\mathrm{I}_{\mathrm{NaW}}$ reduction was unexpected; indeed, loss of CaM affinity for $\mathrm{Ca}^{2+}$ should if anything, increase $\mathrm{I}_{\mathrm{NaW}}$ (48). Notably, CaMKII activity was preserved and even slightly enhanced, probably secondary to the increase in $\mathrm{Ca}^{2+}$ transients amplitude. This supports the view that negative dominance of the mutation only applies to targets, as $\mathrm{Ca}_{\mathrm{v}} 1.2$, binding $\mathrm{CaM}$ in its apo form.

Altogether, these findings clearly confirm loss of $\mathrm{I}_{\mathrm{CaL}} \mathrm{CDI}$ as the mechanism underlying the LQTS phenotype in CaM 


\section{Electrophysiology}

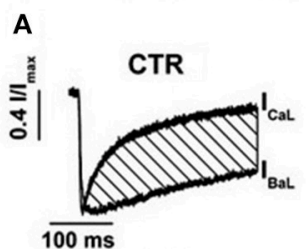

F142L

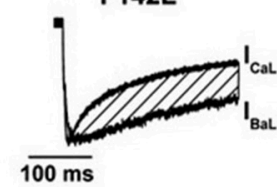

\section{Calcium handling}

D

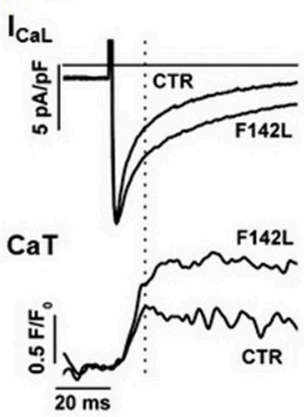

B

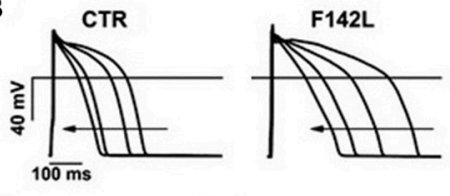

C

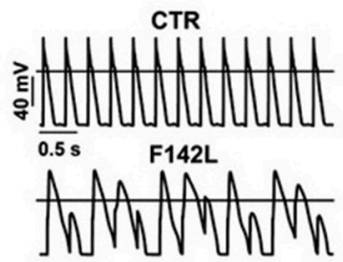

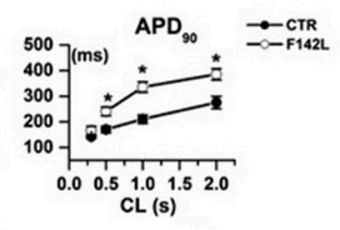

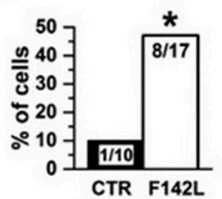

CTR F142L

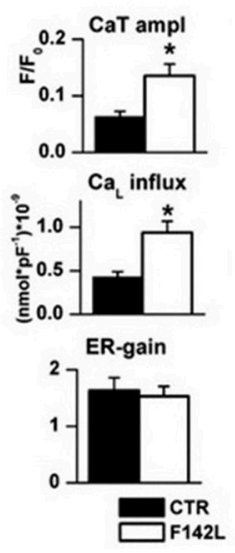

E
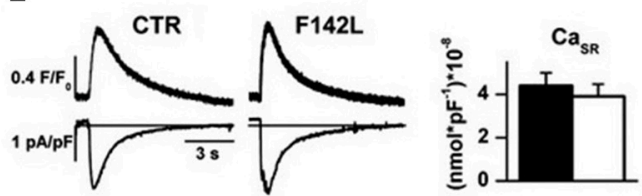

$\mathbf{F}$
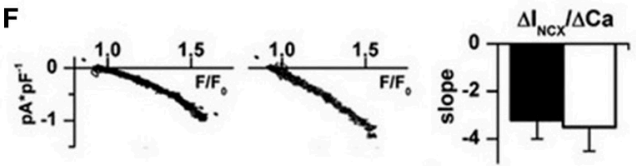

FIGURE 4 | Arrhythmogenic mechanism of CALM1 F142L from experiments in patient-derived hiPSC-CMs. Electrophysiology: (A) ICaL CDI (hatched area) was reduced; (B) CDI impairment led to APD prolongation and inadequate APD shortening at high pacing rate; (C) APD abnormalities led to loss of 1:1 response to fast pacing in a large \% of F142L cells. Calcium handling: (D) Impaired $\mathrm{I}_{\mathrm{CaL}} \mathrm{CDI}$ led to matching increments of $\mathrm{Ca}^{2+}$ influx and of the amplitude of $\mathrm{Ca}^{2+}$ transients (CaT); excitation/release gain (ER-gain) was unchanged, thus suggesting normal RyRs function. (E) In spite of enhanced $\mathrm{Ca}^{2+}$ influx, SR $\mathrm{Ca}^{2+}$ content was unchanged, thus implying compensation by homeostatic mechanisms. (F) The slope of the relationship between $\mathrm{Na}^{+} / \mathrm{Ca}^{2+}$ exchanger current $\left(I_{N C X}\right)$ and $\mathrm{Ca}^{2+}$ concentration was unchanged, to indicate that homeostatic compensation did not involve changes in the expression of the exchanger. Asterisks denote significance of changes.

Modified from ref. Rocchetti et al. (80).

mutations with reduced $\mathrm{Ca}^{2+}$ affinity. To our best knowledge, no hiPSC-CMs studies are thus far available for mutations with a clear-cut CPVT phenotype. It should be considered that, due to immaturity of the structures involved in intracellular $\mathrm{Ca}^{2+}$ handling (e.g., lack of T-tubules) (90), hiPSC-CMs may be less suitable in evaluating CaM mutations leading to SR instability (CPVT phenotype).

\section{CONCLUSIONS AND THERAPEUTIC IMPLICATIONS}

CaM functions as a $\mathrm{Ca}^{2+}$ sensor to maintain physiological $\mathrm{Ca}^{2+}$ levels in cells. In addition to this homeostatic role, CaM signal targeting is required to transduce fundamental cell processes, for which $\mathrm{Ca}^{2+}$-CaM complexing is not necessarily involved, but may still have a modulatory effect. This is possible because of the presence of CaM-binding sequences suitable to allow $\mathrm{CaM}$ to bind multiple targets even in its "apo" form; this generates a quantitatively prevailing "pre-bound" CaM pool. CaM binding to targets occurs with very high specificity, which is required to explain restriction of CaM mutations phenotype to the myocardium and, within it, to specific subcellular targets.

Whereas mutation-induced loss of $\mathrm{Ca}^{2+}$ sensing function is crucial in impairing CDI of sarcolemmal $\mathrm{Ca}^{2+}$ channels (carrying $\mathrm{I}_{\mathrm{CaL}}$ ), it is not required for mutations associated with RyR2 instability. For the latter, changes in CaM affinity for RyR2 channels are apparently more important; however, the direction and even the need for such changes are still unclear. Possibly, mutations induce complex (3D) modifications in the proteinprotein binding interface, of which changes in CaM affinity for the target are just a gross readout. This is a field in which new information is strongly required.

Whereas, "pure" LQTS and CPVT phenotypes suggest abnormal modulation of $\mathrm{I}_{\mathrm{CaL}}$ and $\mathrm{RyR} 2$, respectively, we hypothesize that coexistence of QT prolongation and SR instability (mixed phenotypes) might be accounted for by impaired $\mathrm{I}_{\mathrm{CaL}} \mathrm{CDI}$, possibly with the complement of (very 
common) conditions weakening homeostatic control of intracellular $\mathrm{Ca}^{2+}$.

Based on the information reviewed above, mechanismguided therapeutic approaches to calmodulinopathies should ideally address the interaction of mutant CaM with its targets. Particularly in the case of LQTS-type mutations, this approach is justified by the role of the high target affinity of mutant CaMs in causing negative dominance of the mutation. Tools for this purpose are not available yet, but possibilities exist and are currently explored.

Therapy of CaM mutations with more classical approaches may depend on the phenotype. $\mathrm{I}_{\mathrm{CaL}}$ blockade seems a logical approach in the case of $\mathrm{I}_{\mathrm{CaL}}$ gain of function, resulting from loss of CDI (LQTS phenotype); indeed, verapamil did shorten the QT interval in hiPSC-CMs from CALM1-p.F142L carriers (80). Nonetheless, selective inhibition of the sustained $\mathrm{I}_{\mathrm{CaL}}$ component would be desirable and should be pursued by developing $\mathrm{I}_{\mathrm{CaL}}$ blockers with such a property; as suggested by availability of selective blockade of $\mathrm{I}_{\mathrm{Na}}$ sustained component (91), this should be seen as an achievable goal. Pharmacological treatment of CPVT-type CaM mutations may require RyR2 stabilization, or at least, blunting membrane electrical response to spontaneous $\mathrm{Ca}^{2+}$ release events. This is a long-pursued goal for which no ideal tool has been thus far identified; while agents as flecainide or carvedilol may provide some protection [for review see Zaza and Rocchetti (82)], the search of clinically usable specific RyR2 blockers is currently ongoing.

Because calmodulinopathies have been recently described, information on the clinical efficacy of therapies is not available yet.

\section{FUTURE CHALLENGES}

Calmodulinopathies have undoubtedly attracted high quality, multidisciplinary research; nonetheless, and rather

\section{REFERENCES}

1. Clapham DE. Calcium signaling. Cell (2007) 131:1047-58. doi: 10.1016/j.cell.2007.11.028

2. Ikura M. Calcium binding and conformational response in EF-hand proteins. Trends Biochem Sci. (1996) 21:14-7. doi: 10.1016/S0968-0004(06)80021-6

3. Luby-Phelps K, Hori M, Phelps JM, Won D. $\mathrm{Ca}^{2+}$-regulated dynamic compartmentalization of calmodulin in living smooth muscle cells. J Biol Chem. (1995) 270:21532-8. doi: 10.1074/jbc.270.37.21532

4. Deisseroth K, Heist EK, Tsien RW. Translocation of calmodulin to the nucleus supports CREB phosphorylation in hippocampal neurons. Nature (1998) 392:198. doi: $10.1038 / 32448$

5. Berchtold MW, Villalobo A. The many faces of calmodulin in cell proliferation, programmed cell death, autophagy, and cancer. Biochim Biophys Acta Mol Cell Res. (2014) 1843:398-435. doi: 10.1016/j.bbamcr.2013.10.021

6. Kotta M-C, Sala L, Ghidoni A, Badone B, Ronchi C, Parati G, Zaza A and Crotti L. Calmodulinopathy: A Novel, Life-Threatening Clinical Entity Affecting the Young. Front Cardiovasc Med. (2018). 5:175. doi: $10.3389 /$ fcvm.2018.00175

7. Bers DM. Cardiac excitation-contraction coupling. Nature (2002) 415:198. doi: $10.1038 / 415198 \mathrm{a}$

8. Maier LS, Bers DM. Calcium, calmodulin, and calcium-calmodulin kinase II: heartbeat to heartbeat and beyond. J Mol Cell Cardiol. (2002) 34:919-39. doi: 10.1006/jmcc.2002.2038 unsurprisingly, many questions have yet to be addressed. The present review highlights a few that, in our view, might deserve particular attention.

The role and mechanism of $\mathrm{Na}_{V} 1.5$ dysregulation in CaM mutation-associated phenotypes is elusive. Notably, $\mathrm{I}_{\mathrm{NaL}}$ enhancement, a target for which therapeutic interventions are available, might have a role in both QT prolongation (LQTS phenotype) and SR instability (CPVT phenotype) (91).

The interplay between CaM- and PIP2-dependent modulation of $\mathrm{I}_{\mathrm{Ks}}$ suggests that factors affecting membrane PIP2 levels (e.g., phospholipase-C signaling) potentially influence CaM mutation penetrance. If this were the case, such factors might represent easily accessible therapeutic targets.

The ultimate mechanism of arrhythmia facilitation by loss of $\mathrm{I}_{\mathrm{CaL}} \mathrm{CDI}$, which seems to diverge from what would be expected, has thus far been only superficially addressed.

Finally, the molecular basis of RyR2 dysfunction in the context of CaM mutations remains largely unresolved, thus preventing identification of mechanism-specific targets.

\section{AUTHOR CONTRIBUTIONS}

BB wrote a general manuscript draft. CR focused on the section about CaM modulation of voltage-gated channels. M-CK, LS, and AG provided text and discussion for integration with clinical and genetic aspects of calmodulinopathies. LC and AZ supervised the process and edited the manuscript to its final version.

\section{ACKNOWLEDGMENTS}

This work has been supported by Fondo di Ateneo per la Ricerca (FAR, 2018) of Università Milano-Bicocca to AZ and by the DIMET Ph.D. program to BB.

9. Schwartz PJ, Crotti L, Insolia R. Long-QT syndrome: from genetics to management. Circ Arrhythm Electrophysiol. (2012) 5:868-77. doi: 10.1161/CIRCEP.111.962019

10. Fischer R, Koller M, Flura M, Mathews S, Strehler-Page MA, Krebs J, et al. Multiple divergent mRNAs code for a single human calmodulin. J Biol Chem. (1988) 263:17055-62.

11. Crotti L, Kotta MC. The role of genetics in primary ventricular fibrillation, inherited channelopathies and cardiomyopathies. Int J Cardiol. (2017) 237:45-8. doi: 10.1016/j.ijcard.2017. 03.119

12. Villarroel A, Taglialatela M, Bernardo-Seisdedos G, Alaimo A, Agirre J, Alberdi A, et al. The ever changing moods of calmodulin: how structural plasticity entails transductional adaptability. J Mol Biol. (2014) 426:2717-35. doi: 10.1016/j.jmb.2014.05.016

13. Malmendal A, Linse $\mathrm{S}$, Evenäs J, Forsén $\mathrm{S}$, Drakenberg $\mathrm{T}$. Battle for the EF-hands: magnesium- calcium interference in calmodulin. Biochemistry (1999) 38:11844-50. doi: 10.1021/bi99 09288

14. Tadross MR, Dick IE, Yue DT. Mechanism of local and global $\mathrm{Ca}^{2+}$ sensing by calmodulin in complex with a $\mathrm{Ca}^{2+}$ channel. Cell (2008) 133:1228-40. doi: 10.1016/j.cell.2008.05.025

15. Babu YS, Sack JS, Greenhough TJ, Bugg CE, Means AR, Cook WJ. Three-dimensional structure of calmodulin. Nature (1985) 315:37. doi: $10.1038 / 315037 \mathrm{a} 0$ 
16. Zhang M, Tanaka T, Ikura M. Calcium-induced conformational transition revealed by the solution structure of apo calmodulin. Nat Struct Mol Biol. (1995) 2:758. doi: 10.1038/nsb0995-758

17. Chou JJ, Li S, Klee CB, Bax A. Solution structure of Ca 2+-calmodulin reveals flexible hand-like properties of its domains. Nat Struct Mol Biol. (2001) 8:990. doi: 10.1038/nsb1101-990

18. Yamniuk AP, Vogel HJ. Calmodulin's flexibility allows for promiscuity in its interactions with target proteins and peptides. Mol Biotechnol. (2004) 27:33-57. doi: 10.1385/MB:27:1:33

19. Marshall CB, Nishikawa T, Osawa M, Stathopulos PB, Ikura M. Calmodulin and STIM proteins: two major calcium sensors in the cytoplasm and endoplasmic reticulum. Biochem Biophys Res Commun. (2015) 460:5-21. doi: 10.1016/j.bbrc.2015.01.106

20. Bähler M, Rhoads A. Calmodulin signaling via the IQ motif. FEBS Lett. (2002) 513:107-13. doi: 10.1016/S0014-5793(01)03239-2

21. Gellman SH. On the role of methionine residues in the sequence-independent recognition of nonpolar protein surfaces. Biochemistry (1991) 30:6633-6. doi: 10.1021/bi00241a001

22. Chin D, Means AR. Calmodulin: a prototypical calcium sensor. Trends Cell Biol. (2000) 10:322-8. doi: 10.1016/S0962-8924(00)01800-6

23. Stigler J, Rief M. Calcium-dependent folding of single calmodulin molecules. Proc Natl Acad Sci USA. (2012) 109:17814-9. doi: 10.1073/pnas.1201801109

24. O’Neil KT, DeGrado WF. How calmodulin binds its targets: sequence independent recognition of amphiphilic $\alpha$-helices. Trends Biochem Sci. (1990) 15:59-64. doi: 10.1016/0968-0004(90)90177-D

25. Tidow H, Nissen P. Structural diversity of calmodulin binding to its target sites. FEBS J. (2013) 280:5551-65. doi: 10.1111/febs.12296

26. Valeyev NV, Bates DG, Heslop-Harrison P, Postlethwaite I, Kotov NV. Elucidating the mechanisms of cooperative calcium-calmodulin interactions: a structural systems biology approach. BMC Syst Biol. (2008) 2:48. doi: 10.1186/1752-0509-2-48

27. Beitner R. Calmodulin antagonists and cell energy metabolism in health and disease. Mol Genet Metab. (1998) 64:161-8. doi: 10.1006/mgme.1998.2691

28. Schumacher MA, Rivard AF, Bächinger HP, Adelman JP. Structure of the gating domain of a $\mathrm{Ca} 2+$-activated $\mathrm{K}+$ channel complexed with Ca2+/calmodulin. Nature (2001) 410:1120. doi: 10.1038/35074145

29. Wagner S, Maier LS. Modulation of cardiac $\mathrm{Na}(+)$ and $\mathrm{Ca}(2+)$ currents by CaM and CaMKII. J Cardiovasc Electrophysiol. (2006) 17(Suppl. 1):S26-33. doi: 10.1111/j.1540-8167.2006.00382.x

30. Wang C, Chung BC, Yan H, Wang H-G, Lee S-Y, Pitt GS. Structural analyses of $\mathrm{Ca} 2+/ \mathrm{CaM}$ interaction with $\mathrm{Na} \mathrm{V}$ channel C-termini reveal mechanisms of calcium-dependent regulation. Nat Commun. (2014) 5:4896. doi: $10.1038 /$ ncomms5896

31. Jurado LA, Chockalingam PS, Jarrett HW. Apocalmodulin. Physiol Rev. (1999) 79:661-82. doi: 10.1152/physrev.1999.79.3.661

32. Maier LS, Ziolo MT, Bossuyt J, Persechini A, Mestril R, Bers DM. Dynamic changes in free Ca-calmodulin levels in adult cardiac myocytes. J Mol Cell Cardiol. (2006) 41:451-8. doi: 10.1016/j.yjmcc.2006.04.020

33. Kakiuchi S, Yasuda S, Yamazaki R, Teshima Y, Kanda K, Kakiuchi R, et al. Quantitative determinations of calmodulin in the supernatant and particulate fractions of mammalian tissues. J Biochem. (1982) 92:1041-8. doi: 10.1093/oxfordjournals.jbchem.a134019

34. Bers DM, Perez-Reyes E. Ca channels in cardiac myocytes: structure and function in Ca influx and intracellular Ca release. Cardiovasc Res. (1999) 42:339-60. doi: 10.1016/S0008-6363(99)00038-3

35. Lee K, Marban E, Tsien R. Inactivation of calcium channels in mammalian heart cells: joint dependence on membrane potential and intracellular calcium. J Physiol. (1985) 364:395-411. doi: 10.1113/jphysiol.1985.sp015752

36. Zygmunt AC, Maylie J. Stimulation-dependent facilitation of the high threshold calcium current in guinea-pig ventricular myocytes. J Physiol. (1990) 428:653-71. doi: 10.1113/jphysiol.1990.sp018233

37. Zuehlke RD, Pitt GS, Deisseroth K, Tsien RW, Reuter H. Calmodulin supports both inactivation and facilitation of L-type calcium channels. Nature (1999) 399:159. doi: 10.1038/20200

38. Erickson MG, Alseikhan BA, Peterson BZ, Yue DT. Preassociation of calmodulin with voltage-gated $\mathrm{Ca}(2+)$ channels revealed by FRET in single living cells. Neuron (2001) 31:973-85. doi: 10.1016/S0896-6273(01) 00438-X
39. Liang H, DeMaria CD, Erickson MG, Mori MX, Alseikhan BA, Yue DT. Unified mechanisms of $\mathrm{Ca} 2+$ regulation across the $\mathrm{Ca} 2+$ channel family. Neuron (2003) 39:951-60. doi: 10.1016/S0896-6273(03)00560-9

40. Lee T-S, Karl R, Moosmang S, Lenhardt P, Klugbauer N, Hofmann F, et al. Calmodulin kinase II is involved in voltage-dependent facilitation of the Ltype cav1. 2 calcium channel identification of the phosphorylation sites. J Biol Chem. (2006) 281:25560-67. doi: 10.1074/jbc.M508661200

41. Erxleben C, Liao Y, Gentile S, Chin D, Gomez-Alegria C, Mori Y, et al. Cyclosporin and timothy syndrome increase mode 2 gating of CaV1. 2 calcium channels through aberrant phosphorylation of S6 helices. Proc Natl Acad Sci USA. (2006) 103:3932-7. doi: 10.1073/pnas.0511322103

42. Shamgar L, Ma L, Schmitt N, Haitin Y, Peretz A, Wiener R, et al. Calmodulin is essential for cardiac IKS channel gating and assembly: impaired function in long-QT mutations. Circ Res. (2006) 98:1055-63. doi: 10.1161/01.RES.0000218979.40770.69

43. Tobelaim WS, Dvir M, Lebel G, Cui M, Buki T, Peretz A, et al. Ca(2+)Calmodulin and PIP2 interactions at the proximal C-terminus of Kv7 channels. Channels (2017) 11:686-95. doi: 10.1080/19336950.2017.1388478

44. Chang A, Abderemane-Ali F, Hura GL, Rossen ND, Gate RE, Minor Jr DL. A calmodulin C-Lobe Ca2+-dependent switch governs Kv7 channel function. Neuron (2018) 97:836-52.e836. doi: 10.1016/j.neuron.2018.01.035

45. Ciampa EJ, Welch RC, Vanoye CG, George AL. KCNE4 juxtamembrane region is required for interaction with calmodulin and for functional suppression of KCNQ1. J Biol Chem. (2011) 286:4141-9. doi: 10.1074/jbc.M110.158865

46. Shugg T, Johnson DE, Shao M, Lai X, Witzmann F, Cummins TR, et al. Calcium/calmodulin-dependent protein kinase II regulation of IKs during sustained beta-adrenergic receptor stimulation. Heart Rhythm (2018) 15:895904. doi: 10.1016/j.hrthm.2018.01.024

47. Kim J, Ghosh S, Liu H, Tateyama M, Kass RS, Pitt GS. Calmodulin mediates $\mathrm{Ca} 2+$ sensitivity of sodium channels. J Biol Chem. (2004) 279:45004-12. doi: 10.1074/jbc.M407286200

48. Shah VN, Wingo TL, Weiss KL, Williams CK, Balser JR, Chazin WJ. Calciumdependent regulation of the voltage-gated sodium channel hH1: intrinsic and extrinsic sensors use a common molecular switch. Proc Natl Acad Sci USA. (2006) 103:3592-7. doi: 10.1073/pnas.0507397103

49. Lanner JT, Georgiou DK, Joshi AD, Hamilton SL. Ryanodine receptors: structure, expression, molecular details, and function in calcium release. Cold Spring Harb Perspect Biol. (2010) 2:a003996. doi: 10.1101/cshperspect.a003996

50. Soeller C, Crossman D, Gilbert R, Cannell MB. Analysis of ryanodine receptor clusters in rat and human cardiac myocytes. Proc Natl Acad Sci USA. (2007) 104:14958-63. doi: 10.1073/pnas.0703016104

51. Louch WE, Stokke MK, Sjaastad I, Christensen G, Sejersted OM. No rest for the weary: diastolic calcium homeostasis in the normal and failing myocardium. Physiology (2012) 27:308-23. doi: 10.1152/physiol.00021.2012

52. Franzini-Armstrong C, Protasi F, Ramesh V. Shape, size, and distribution of $\mathrm{Ca} 2+$ release units and couplons in skeletal and cardiac muscles. Biophys J. (1999) 77:1528-39. doi: 10.1016/S0006-3495(99)77000-1

53. Bers DM, Stiffel VM. Ratio of ryanodine to dihydropyridine receptors in cardiac and skeletal muscle and implications for EC coupling. Am J Physiol Cell Physiol. (1993) 264:C1587-93. doi: 10.1152/ajpcell.1993.264.6.C1587

54. Balshaw DM, Xu L, Yamaguchi N, Pasek DA, Meissner G. Calmodulin binding and inhibition of cardiac muscle calcium release channel (ryanodine receptor). J Biol Chem. (2001) 276:20144-53. doi: 10.1074/jbc.M010771200

55. Xiong H, Feng X, Gao L, Xu L, Pasek DA, Seok J-H, et al. Identification of a two EF-hand $\mathrm{Ca} 2+$ binding domain in lobster skeletal muscle ryanodine receptor/Ca2 + release channel. Biochemistry (1998) 37:4804-14. doi: 10.1021/bi971198b

56. Xu L, Gomez AC, Pasek DA, Meissner G, Yamaguchi N. Two EFhand motifs in ryanodine receptor calcium release channels contribute to isoform-specific regulation by calmodulin. Cell Calcium (2017) 66:62-70. doi: 10.1016/j.ceca.2017.05.013

57. Gyorke S, Terentyev D. Modulation of ryanodine receptor by luminal calcium and accessory proteins in health and cardiac disease. Cardiovasc Res. (2008) 77:245-55. doi: 10.1093/cvr/cvm038

58. Li P, Chen SW. Molecular basis of $\mathrm{Ca}^{2+}$ activation of the mouse cardiac Ca2+ release channel (ryanodine receptor). J Gen Physiol. (2001) 118:33-44. doi: 10.1085/jgp.118.1.33 
59. Guo W, Sun B, Xiao Z, Liu Y, Wang Y, Zhang L, et al. The EFhand $\mathrm{Ca} 2+$ binding domain is not required for cytosolic $\mathrm{Ca}^{2+}$ activation of the cardiac ryanodine receptor. J Biol Chem. (2016) 291:2150-60. doi: 10.1074/jbc.M115.693325

60. Zalk R, Lehnart SE, Marks AR. Modulation of the ryanodine receptor and intracellular calcium. Annu Rev Biochem. (2007) 76:367-85. doi: 10.1146/annurev.biochem.76.053105.094237

61. Buratti R, Prestipino G, Menegazzi P, Treves S, Zorzato F. Calciumdependent activation of skeletal-muscle $\mathrm{Ca}^{2+}$ release channel (ryanodine receptor) by calmodulin. Biochem Biophys. Res Commun. (1995) 213:1082-90. doi: 10.1006/bbrc.1995.2238

62. Tripathy A, Xu L, Mann G, Meissner G. Calmodulin activation and inhibition of skeletal muscle $\mathrm{Ca}^{2+}$ release channel (ryanodine receptor). Biophys J. (1995) 69:106-19. doi: 10.1016/S0006-3495(95)79880-0

63. Walweel K, Oo YW, Laver DR. The emerging role of calmodulin regulation of RyR2 in controlling heart rhythm, the progression of heart failure and the antiarrhythmic action of dantrolene. Clin Exp Pharmacol Physiol. (2017) 44:135-42. doi: 10.1111/1440-1681.12669

64. Xu L, Meissner G. Mechanism of calmodulin inhibition of cardiac sarcoplasmic reticulum $\mathrm{Ca} 2+$ release channel (ryanodine receptor). Biophys J. (2004) 86:797-804. doi: 10.1016/S0006-3495(04)74155-7

65. Yamaguchi N, Xu L, Pasek DA, Evans KE, Meissner G. Molecular basis of calmodulin binding to cardiac muscle $\mathrm{Ca}^{2+}$ release channel (ryanodine receptor). J Biol Chem. (2003) 278:23480-6. doi: 10.1074/jbc.M301125200

66. Oda T, Yang Y, Nitu FR, Svensson B, Lu X, Fruen BR, et al. In cardiomyocytes, binding of unzipping peptide activates ryanodine receptor 2 and reciprocally inhibits calmodulin binding. Circ Res. (2013) 112:487-97. doi: 10.1161/CIRCRESAHA.111.300290

67. Oda T, Yang Y, Uchinoumi H, Thomas DD, Chen-Izu Y, Kato T, et al. Oxidation of ryanodine receptor (RyR) and calmodulin enhance Ca release and pathologically alter, RyR structure and calmodulin affinity. J Mol Cell Cardiol. (2015) 85:240-8. doi: 10.1016/j.yjmcc.2015.06.009

68. Gangopadhyay JP, Ikemoto N. Interaction of the Lys(3614)-Asn(3643) calmodulin-binding domain with the Cys(4114)-Asn(4142) region of the type 1 ryanodine receptor is involved in the mechanism of Ca2+/agonist-induced channel activation. Biochem J. (2008) 411:415-23. doi: 10.1042/BJ20071375

69. Huang X, Fruen B, Farrington DT, Wagenknecht T, Liu Z. Calmodulinbinding locations on the skeletal and cardiac ryanodine receptors. J Biol Chem. (2012) 287:30328-35. doi: 10.1074/jbc.M112.383109

70. Wehrens XH, Lehnart SE, Reiken SR, Marks AR. Ca2+/calmodulindependent protein kinase II phosphorylation regulates the cardiac ryanodine receptor. Circ Res. (2004) 94:e61-70. doi: 10.1161/01.RES.0000125626.33738.E2

71. Terentyev D, Gyorke I, Belevych AE, Terentyeva R, Sridhar A, Nishijima Y, et al. Redox modification of ryanodine receptors contributes to sarcoplasmic reticulum Ca2 + leak in chronic heart failure. Circ Res. (2008) 103:1466-72. doi: 10.1161/CIRCRESAHA.108.184457

72. Makita N, Yagihara N, Crotti L, Johnson CN, Beckmann B-M, Roh MS, et al. Novel calmodulin mutations associated with congenital arrhythmia susceptibilityclinical perspective. Circ Genom Prec Med. (2014) 7:466-74. doi: 10.1161/CIRCGENETICS.113.000459

73. Crotti L, Johnson CN, Graf E, De Ferrari GM, Cuneo BF, Ovadia $\mathrm{M}$, et al. Calmodulin mutations associated with recurrent cardiac arrest in infants. Circulation (2013) 127:1009-17. doi: 10.1161/CIRCULATIONAHA.112.001216

74. Sondergaard MT, Sorensen AB, Skov LL, Kjaer-Sorensen K, Bauer MC, Nyegaard $M$, et al. Calmodulin mutations causing catecholaminergic polymorphic ventricular tachycardia confer opposing functional and biophysical molecular changes. FEBS J. (2015) 282:803-16. doi: $10.1111 /$ febs. 13184

75. Marsman RF, Barc J, Beekman L, Alders M, Dooijes D, van den Wijngaard A, et al. A mutation in CALM1 encoding calmodulin in familial idiopathic ventricular fibrillation in childhood and adolescence. J Am Coll Cardiol. (2014) 63:259-66. doi: 10.1016/j.jacc.2013.07.091

76. Reed GJ, Boczek NJ, Etheridge SP, Ackerman MJ. CALM3 mutation associated with long QT syndrome. Heart Rhythm (2015) 12:419-22. doi: 10.1016/j.hrthm.2014.10.035

77. Limpitikul WB, Dick IE, Joshi-Mukherjee R, Overgaard MT, George AL, Yue DT. Calmodulin mutations associated with long QT syndrome prevent inactivation of cardiac L-type Ca2+ currents and promote proarrhythmic behavior in ventricular myocytes. J Mol Cell Cardiol. (2014) 74:115-24. doi: 10.1016/j.yjmcc.2014.04.022

78. Pipilas DC, Johnson CN, Webster G, Schlaepfer J, Fellmann F, Sekarski $\mathrm{N}$, et al. Novel calmodulin mutations associated with congenital long QT syndrome affect calcium current in human cardiomyocytes. Heart Rhythm (2016) 13:2012-9. doi: 10.1016/j.hrthm.2016.06.038

79. Boczek NJ, Gomez-Hurtado N, Ye D, Calvert ML, Tester DJ, Kryshtal D, et al. Spectrum and prevalence of CALM1-, CALM2-, and CALM3encoded calmodulin (CaM) variants in long QT syndrome (LQTS) and functional characterization of a novel LQTS-associated CaM missense variant, E141G. Circ Cardiovasc Genet. (2016) 9:136-46. doi: 10.1161/CIRCGENETICS.115.001323

80. Rocchetti M, Sala L, Dreizehnter L, Crotti L, Sinnecker D, Mura M, et al. Elucidating arrhythmogenic mechanisms of long-QT syndrome CALM1F142L mutation in patient-specific induced pluripotent stem cell-derived cardiomyocytes. Cardiovasc Res. (2017) 113:531-41. doi: 10.1093/cvr/cvx006

81. Priori SG, Napolitano C, Tiso N, Memmi M, Vignati G, Bloise R, et al. Mutations in the cardiac ryanodine receptor gene (hRyR2) underlie catecholaminergic polymorphic ventricular tachycardia. Circulation (2001) 103:196-200. doi: 10.1161/01.CIR.103.2.196

82. Zaza A, Rocchetti M. Calcium store stability as an antiarrhythmic endpoint. Curr Pharm Des. (2015) 21:1053-61. doi: $10.2174 / 1381612820666141029100650$

83. Nishio M, Ruch SW, Kelly JE, Aistrup GL, Sheehan K, Wasserstrom JA. Ouabain increases sarcoplasmic reticulum calcium release in cardiac myocytes. J Pharmacol Exp Ther. (2004) 308:1181-90. doi: 10.1124/jpet.103.060004

84. Nyegaard M, Overgaard MT, Søndergaard MT, Vranas M, Behr ER, Hildebrandt LL, et al. Mutations in calmodulin cause ventricular tachycardia and sudden cardiac death. Am J Hum Genet. (2012) 91:703-12. doi: 10.1016/j.ajhg.2012.08.015

85. Gomez-Hurtado N, Boczek NJ, Kryshtal DO, Johnson CN, Sun J, Nitu FR, et al. Novel CPVT-associated calmodulin mutation in CALM3 (CALM3A103V) activates arrhythmogenic Ca waves and sparks. Circ Arrhythm Electrophysiol. (2016) 9:e004161. doi: 10.1161/CIRCEP.116.004161

86. Hwang H-S, Nitu FR, Yang Y, Walweel K, Pereira L, Johnson CN, et al. Divergent regulation of RyR2 calcium release channels by arrhythmogenic human calmodulin missense mutants. Circ Res. (2014) 114:1114-24. doi: 10.1161/CIRCRESAHA.114.303391

87. Nomikos M, Thanassoulas A, Beck K, Vassilakopoulou V, Hu H, Calver BL, et al. Altered RyR2 regulation by the calmodulin F90L mutation associated with idiopathic ventricular fibrillation and early sudden cardiac death. FEBS Lett. (2014) 588:2898-902. doi: 10.1016/j.febslet.2014.07.007

88. Yu CC, Ko JS, Ai T, Tsai WC, Chen Z, Rubart M, et al. Arrhythmogenic calmodulin mutations impede activation of small-conductance calciumactivated potassium current. Heart Rhythm (2016) 13:1716-23. doi: 10.1016/j.hrthm.2016.05.009

89. Yamamoto Y, Makiyama T, Harita T, Sasaki K, Wuriyanghai Y, Hayano M, et al. Allele-specific ablation rescues electrophysiological abnormalities in a human iPS cell model of long-QT syndrome with a CALM2 mutation. Hum Mol Genet. (2017) 26:1670-7. doi: 10.1093/hmg/ddx073

90. Koivumäki JT, Naumenko N, Tuomainen T, Takalo J, Oksanen M, Puttonen $\mathrm{KA}$, et al. Structural immaturity of human iPSC-derived cardiomyocytes: in silico investigation of effects on function and disease modeling. Front Physiol. (2018) 9:80. doi: 10.3389/fphys.2018.00080

91. Zaza A, Rocchetti M. The late $\mathrm{Na}+$ current-origin and pathophysiological relevance. Cardiovasc Drugs Ther. (2013) 27:61-8. doi: $10.1007 /$ s10557-012-6430-0

Conflict of Interest Statement: The authors declare that the research was conducted in the absence of any commercial or financial relationships that could be construed as a potential conflict of interest.

Copyright (C) 2018 Badone, Ronchi, Kotta, Sala, Ghidoni, Crotti and Zaza. This is an open-access article distributed under the terms of the Creative Commons Attribution License (CC BY). The use, distribution or reproduction in other forums is permitted, provided the original author(s) and the copyright owner(s) are credited and that the original publication in this journal is cited, in accordance with accepted academic practice. No use, distribution or reproduction is permitted which does not comply with these terms. 